\title{
Psychopharmacology and adverse effects of antipsychotic long-acting injections: a review
}

David Taylor

\section{Background}

Depot antipsychotics are widely used in clinical practice Long-acting formulations of second-generation antipsychotics are now being developed and introduced.

\section{Aims}

To review the pharmacology, pharmacokinetics and adverse effect profiles of currently available antipsychotic long-acting injections (LAIS).

\section{Method}

The psychopharmacological properties of first- and secondgeneration antipsychotic LAls are reviewed using data available up to October 2008.

\section{Results}

First-generation antipsychotic (FGA) LAls are associated with a high rate of acute and chronic movement disorders. Risperidone LAl is better tolerated in this respect, but is associated with hyperprolactinaemia and weight gain. Olanzapine LAl causes weight gain and other metabolic effects but appears not to be associated with an important incidence of movement disorders.

\section{Conclusions}

Dosing of LAls is complicated by delayed release of drug, changes in plasma levels without change in dose, and by the lack of data establishing clear dose requirements. All LAls offer the prospect of assured adherence (although patients may still default on treatment) but their use is complicated by adverse effects, complex pharmacokinetics and confusion over dose-response relationships.

\section{Declaration of interest}

D.T. has received research funding and consultancy honoraria from AstraZeneca, Bristol-Myers Squibb, JanssenCilag, Lundbeck, Novartis, Eli Lilly and Sanofi-Aventis.
There are currently eight antipsychotic long-acting injections (LAIs) in widespread use around the world. Six of these are LAI preparations of first-generation antipsychotics (FGAs), including flupentixol, fluphenazine, haloperidol, perphenazine, pipotiazine and zuclopenthixol, and the remaining two are LAI formulations of the second-generation antipsychotics (SGAs) risperidone and olanzapine. The dosing characteristics of these LAIs are summarised in Table 1.

\section{Pharmacokinetic characteristics}

Almost all antipsychotics have short plasma half-lives of 1-2 days at most. This means that antipsychotics have to be administered frequently in order to attain and maintain therapeutic effects. Although the elimination half-lives of these drugs cannot be altered to any important degree, chemical manipulation of the parent compound and changes in pharmaceutical formulation can significantly alter drug release or absorption characteristics. When absorption and/or release are extensively prolonged, effective plasma half-life can be extended (half-life is dependent on release rather than elimination).

Some FGAs possess a terminal alcohol $(-\mathrm{OH})$ group which allows them to be combined with carboxylic acids by a process of esterification. Long-chain esters show high oil solubility and low water solubility. Long-acting injectable formulations of FGAs contain long-chain drug esters (e.g. decanoate, palmitate) dissolved in a vegetable oil. When injected intramuscularly, the oil forms a depot of drug: the drug ester slowly diffuses into the blood stream and is then rapidly hydrolysed to release the parent drug. ${ }^{1}$ Most SGAs lack terminal $-\mathrm{OH}$ groups suitable for esterification. Modification of release characteristics is brought about by other means: encapsulating the drug into a biodegradable polymer (risperidone) or injecting a suspension (i.e. water-insoluble particulate matter in water) of drug compound (olanzapine pamoate).

\section{First-generation LAls}

\section{Flupentixol}

Flupentixol is a thioxanthine antipsychotic. Flupentixol LAI is formulated as flupentixol decanoate in a low-viscosity vegetable oil (fractionated coconut oil). Flupentixol decanoate provides peak plasma levels 3-7 days after intramuscular injection and shows an apparent half-life of 17 days. ${ }^{2,3}$ Steady-state plasma levels can be expected to be achieved after 2 months or so of regular dosing. In practice, plasma levels may show marked variability independent of dose changes. ${ }^{4}$

\section{Fluphenazine}

Fluphenazine is a piperazine phenothiazine compound. Fluphenazine decanoate is available as an LAI in sesame oil. Plasma levels peak within $24 \mathrm{~h}$ of intramuscular injection, ${ }^{5}$ and the half-life is approximately 7-14 days. ${ }^{1,6}$ Plasma levels obtained vary up to 40 -fold in patients receiving the same dose. ${ }^{5}$ Smoking significantly reduces plasma fluphenazine levels.

\section{Haloperido}

Haloperidol is a butyrophenone and is available as haloperidol decanoate in sesame oil. Peak plasma levels are seen up to 7 days after intramuscular injection and plasma half-life is around 3 weeks. ${ }^{1,2}$ Steady-state plasma levels can be expected to be reached after 2-3 months of regular dosing. ${ }^{8}$ As with fluphenazine, clearance of haloperidol is significantly increased by smoking. ${ }^{9}$ Nonetheless, variation in plasma levels is smaller in patients receiving haloperidol decanoate than in those receiving oral haloperidol. ${ }^{10}$

\section{Perphenazine}

Perphenazine is a piperazine phenothiazine available as perphenazine decanoate in sesame oil, used mainly in northern Europe 


\begin{tabular}{|c|c|c|c|c|c|c|c|}
\hline & $\begin{array}{l}\text { Time to } \\
\text { peak, } \\
\text { days }\end{array}$ & $\begin{array}{l}\text { Plasma } \\
\text { half-life, } \\
\text { days }\end{array}$ & $\begin{array}{l}\text { Time to } \\
\text { steady state, } \\
\text { months }\end{array}$ & $\begin{array}{l}\text { Test } \\
\text { dose, } \\
\text { mg }\end{array}$ & $\begin{array}{l}\text { Typical clinical } \\
\text { dose per } \\
2 \text { weeks, mg }\end{array}$ & $\begin{array}{l}\text { Licensed dosing } \\
\text { intervals (UK), } \\
\text { weeks }\end{array}$ & Comments \\
\hline \multicolumn{8}{|l|}{ First-generation antipsychotics } \\
\hline Flupentixol decanoate & $3-7$ & $\sim 17$ & 2 & 20 & 60 & $2-4$ & \multirow{3}{*}{$\begin{array}{l}\text { Available as low-volume injection } \\
\text { Available as concentrate }\end{array}$} \\
\hline Fluphenazine decanoate & 1 & $7-14$ & 2 & 12.5 & 50 & $2-5$ & \\
\hline Haloperidol decanoate & 7 & $\sim 21$ & $2-3$ & Not stated & 100 & $2-4$ & \\
\hline Perphenazine decanoate & $1-7$ & $\sim 14$ & 3 & Not stated & 150 & $2-4$ & \multirow[t]{2}{*}{ Not used in UK or USA } \\
\hline Pipotiazine palmitate & $7-14$ & $\sim 14$ & 2 & 25 & 50 & 4 & \\
\hline Zuclopenthixol decanoate & 7 & $\sim 14$ & 2 & 100 & 300 & $1-4$ & Available as concentrate \\
\hline \multicolumn{8}{|c|}{ Second-generation antipsychotics } \\
\hline Olanzapine pamoate & $2-4$ & $14-28$ & $2-3$ & $\begin{array}{c}\text { Not } \\
\text { recommended }\end{array}$ & 300 & 2 or 4 & \multirow{2}{*}{$\begin{array}{l}\text { Limited clinical experience } \\
\text { as recently introduced } \\
\text { Drug release delayed for 2-3 } \\
\text { weeks }\end{array}$} \\
\hline Risperidone microspheres & 28 & $4-6$ & 2 & $\begin{array}{c}\text { Not } \\
\text { appropriate }\end{array}$ & 37.5 & 2 & \\
\hline
\end{tabular}

and Scandinavia. After intramuscular injection, peak plasma levels are obtained in 1-7 days and the half-life is approximately 2 weeks. ${ }^{11}$ Steady-state levels are obtained after 3 months. ${ }^{12}$ Variations in plasma levels during regular dosing are small, ${ }^{11}$ and plasma levels are directly correlated with dose. ${ }^{13}$

\section{Pipotiazine}

Pipotiazine is a piperidine phenothiazine antipsychotic. The LAI formulation contains pipotiazine palmitate in coconut oil. This provides peak plasma levels after 1-2 weeks although no drug is released for at least 3 days. ${ }^{14}$ Other sources suggest peak levels are seen within 24 h. ${ }^{1,15}$ Plasma half-life is around 2 weeks and the time to steady state is 2 months. ${ }^{1,14,15}$

\section{Zuclopenthixol}

Like flupentixol, zuclopenthixol is a thioxanthine compound. Zuclopenthixol LAI is formulated as the decanoate ester dissolved in thin vegetable oil (fractionated coconut oil). Peak plasma levels of zuclopenthixol are achieved a week after injection. ${ }^{16}$ Plasma half-life has been estimated at 7.4 days and 19 days. ${ }^{17,18}$ Zuclopenthixol LAI shows moderate inter- and intra-individual differences in plasma levels, ${ }^{19}$ and marked differences between peak and trough plasma levels when given every 2 weeks (peak levels more than 3 times higher than trough). ${ }^{17}$ Steady-state plasma levels are achieved after around 2 months of regular dosing. ${ }^{19}$

\section{Second-generation LAls}

\section{Olanzapine}

Olanzapine LAI is a salt of pamoic acid and olanzapine (olanzapine pamoate) suspended in water. This formulation provides peak plasma levels some $2-4$ days after intramuscular administration and a plasma half-life of $2-4$ weeks. ${ }^{20}$ Plasma levels obtained are directly proportional to dose given and time to steady state is around 2-3 months. ${ }^{20}$ In 2-weekly dosing trough levels are around $50 \%$ of peak level; in monthly dosing trough levels are $75 \%$ lower than peak. ${ }^{20}$ Olanzapine pamoate dissociates readily in aqueous environments (e.g. plasma) so its pharmacokinetic properties depend on the method of administration (see below).

\section{Risperidone}

As with olanzapine LAI, the formulation of risperidone LAI is materially different from the ester-in-oil preparations of firstgeneration antipsychotics so far described. Its LAI formulation contains risperidone encapsulated into polymeric microspheres which requires cold storage to retain its intended release characteristics. These microspheres are made up of biodegradable copolymer which is slowly hydrolysed in vivo to release risperidone. ${ }^{21}$ After intramuscular injection a small amount of risperidone is released from the surface of the microspheres, ${ }^{21}$ but then further release is delayed for 2-3 weeks, during which time erosion of the microspheres takes place. In 2-weekly dosing peak plasma levels are seen at around 4 weeks after the first injection and the plasma half-life is of the order of 4-6 days. ${ }^{22}$ Steady-state plasma levels are obtained after 8 weeks, at which time peak-to-trough levels vary threefold. ${ }^{22}$

\section{Dose and administration}

As with oral antipsychotics, dosing requirements for LAIs in individuals vary enormously. Examination of population data (as below) can provide some guidance on optimum dosing, but individual variation should always be borne in mind and dose adjustments should be according to patient response and tolerability.

Flupentixol decanoate is given initially as a test dose of $20 \mathrm{mg}$. After 7 days a further dose of $20-40 \mathrm{mg}$ is given. Dosing is then at intervals of 2-4 weeks, at doses ranging from $50 \mathrm{mg}$ every 4 weeks to $400 \mathrm{mg}$ weekly. Dose-response relationships are less than clear. One study showed $40 \mathrm{mg}$ every 2 weeks to be as effective in relapse prevention as $40 \mathrm{mg}$ every 4 weeks. ${ }^{23}$ Other trials lend some support to the use of $40 \mathrm{mg}$ every 2 weeks as the optimal dose of this compound. ${ }^{24,25}$ Both studies were double-blind. In one study, $40 \mathrm{mg}$ every 2 weeks was shown to be as effective in improving 'ward behaviour' and better tolerated than $200 \mathrm{mg}$ every 2 weeks in female patients over 13 weeks' treatment. ${ }^{24}$ In the other study a $50 \%$ dose reduction to $6 \mathrm{mg}$ per week led to substantially increased risk of relapse compared with participants not undergoing dose reduction receiving on average $9 \mathrm{mg}$ per week. ${ }^{25}$ In contrast, another study in patients stabilised on higher doses showed that reducing the dose of flupentixol below $200 \mathrm{mg}$ every 2 weeks significantly increased the risk of relapse. ${ }^{26}$ This study was also a double-blind randomised trial but included only 18 participants.

Fluphenazine decanoate is initiated with a test dose of $12.5 \mathrm{mg}$. Maintenance doses are in the range $12.5-100 \mathrm{mg}$ given every 2-5 weeks - the maximum dose is thus $100 \mathrm{mg}$ every 2 weeks. Much lower doses appear to be effective $-25 \mathrm{mg}$ every 2 weeks is no more effective than $25 \mathrm{mg}$ every 6 weeks. ${ }^{27}$ There is some support for even lower doses, ${ }^{28}$ but controlled trials suggest that doses substantially less than $25 \mathrm{mg}$ every 2 weeks greatly increase the risk of relapse. ${ }^{29,30}$ 
For haloperidol decanoate no formal test dose is specified. Treatment is usually begun with a dose of $50 \mathrm{mg}$ and maintenance doses are usually in the range $50-300 \mathrm{mg}$ every 4 weeks (in the USA up to 20 times the previous oral haloperidol dose can be used). Doses of around $100 \mathrm{mg}$ every 4 weeks are probably optimal; ${ }^{31,32}$ relapse prevention is not improved by higher doses. A dose of $25 \mathrm{mg}$ every 4 weeks is probably ineffective, ${ }^{31}$ whereas doses of around $50 \mathrm{mg}$ every 4 weeks may be effective in some patients. $^{31,33}$

Perphenazine plasma levels of $1-5 \mathrm{nmol} / \mathrm{l}$ have been associated with good therapeutic response, ${ }^{34}$ although a higher therapeutic range has been suggested. ${ }^{35}$ In a study that aimed to discover the minimum effective dose of perphenazine decanoate, it was found that this was around $100 \mathrm{mg}$ every 2 weeks (range 21.6270.5 per 2 weeks). ${ }^{13}$ Plasma levels ranged from around $2 \mathrm{nmol} / \mathrm{l}$ to $18 \mathrm{nmol} / \mathrm{l}$ depending on dose. In a further study of responding patients receiving $108.5 \mathrm{mg}$ perphenazine decanoate every 2 weeks, plasma levels averaged $5 \mathrm{nmol} / \mathrm{l}$ and ranged from around $2 \mathrm{nmol} / \mathrm{l}$ to $6 \mathrm{nmol} / \mathrm{l}^{11}$ Other studies have shown that doses of around $100 \mathrm{mg}$ every 2 weeks are effective and provide plasma levels in the range $3-11 \mathrm{nmol} / \mathrm{l}^{36,37}$

Pipotiazine palmitate is usually first given as a test dose of $25 \mathrm{mg}$. Maintenance doses are usually within the range $50-200 \mathrm{mg}$ every month (up to $250 \mathrm{mg}$ in Canada). The dose-response relationship is poorly defined. An early study suggested that the optimal dose of pipotiazine palmitate was between $100 \mathrm{mg}$ and $600 \mathrm{mg}$ every 4 weeks. ${ }^{38}$ Later trials found doses of $50-200 \mathrm{mg}$ every 4 weeks to be adequately effective..$^{39,40}$

Zuclopenthixol decanoate is initiated with a test dose of $100 \mathrm{mg}$ and maintenance doses vary from $200 \mathrm{mg}$ every 4 weeks to $600 \mathrm{mg}$ a week. In an open dose-reduction study of 23 patients, the minimum effective dose was shown to be, on average, $200 \mathrm{mg}$ every 2 weeks (range $60-400 \mathrm{mg}$ ). ${ }^{41}$ In practice zuclopenthixol is often given at weekly or 2-weekly intervals. However, doses of 100-600 mg (mean $284 \mathrm{mg}$ ) given every 4 weeks have been shown to be as effective in preventing relapse as haloperidol decanoate (38-200 mg per month). ${ }^{42}$ Fortnightly or monthly administration thus seems reasonable in practice in the out-patient setting for maintenance treatment.

Olanzapine pamoate is licensed to be given in doses ranging from $150 \mathrm{mg}$ every 2 weeks to $300 \mathrm{mg}$ every 2 weeks. Supplementation with oral olanzapine is not usually required owing to prompt early release of olanzapine from the formulation. In a placebocontrolled trial, doses of $210 \mathrm{mg}$ per 2 weeks, $300 \mathrm{mg}$ per 2 weeks and $405 \mathrm{mg}$ per 4 weeks were equally effective and well tolerated. ${ }^{43}$

Risperidone LAI is usually begun at a dose of $25 \mathrm{mg}$ or $37.5 \mathrm{mg}$ according to the dose of antipsychotic previously received. Ideally, patients should first be treated with oral risperidone to assess dose requirements and tolerability. Supplementary oral antipsychotic treatment is required for 4-6 weeks after the first risperidone LAI. Dosing is licensed only at 2-weekly intervals, although there is emerging evidence that monthly dosing might be effective. ${ }^{44}$ Doses of $25 \mathrm{mg}, 37.5 \mathrm{mg}, 50 \mathrm{mg}$ and $75 \mathrm{mg}$ every 2 weeks have been shown to be broadly equal in effectiveness in clinical trials. ${ }^{45-47}$ The maximum licensed dose is $50 \mathrm{mg}$ every 2 weeks (a dose of $75 \mathrm{mg}$ per 2 weeks causes significantly more extrapyramidal symptoms). ${ }^{46}$ In practice, the lowest licensed dose of $25 \mathrm{mg}$ every 2 weeks may be relatively ineffective. ${ }^{48,49}$

\section{Pharmacodynamics}

Both first-generation and second-generation antipsychotics administered by any route are presumed to exert their antipsychotic action by blocking central dopamine receptors of the
$\mathrm{D}_{2}$ receptor subtype. All LAIs are potent in vitro antagonists of $\mathrm{D}_{2}$ receptors. In vivo, potency in humans is usually determined by measuring striatal $\mathrm{D}_{2}$ occupancy using methods such as positron emission tomography (PET) and single photon emission computerised tomography (SPECT). Therapeutic response seems to be associated with striatal $\mathrm{D}_{2}$ occupancies of $65 \%$ or greater, whereas hyperprolactinaemia and extrapyramidal side-effects occur at occupancies of $72 \%$ and $78 \%$ respectively, ${ }^{50}$ although these observations are based on a single study including a limited number of individuals. Antipsychotic action may not be derived from activity in the striatum, but striatal occupancies correlate closely with response to antipsychotic treatment. ${ }^{51}$

Few studies have examined striatal $\mathrm{D}_{2}$ occupancy afforded by the use of LAIs. The earliest PET study found occupancies of 50$80 \%$ for patients receiving haloperidol decanoate $50-200 \mathrm{mg}$ a month, pipotiazine palmitate $100 \mathrm{mg}$ a month and fluphenazine decanoate $200 \mathrm{mg}$ a month. ${ }^{52}$ Occupancy levels appeared to increase in the 20 days following injection. A later study of four patients receiving $30-50 \mathrm{mg}$ haloperidol decanoate a month showed that peak $D_{2}$ occupancies were in the range $66-82 \%$ a week after injection. ${ }^{53}$ In an extension of this study $(n=8$, including two patients who participated in the previous study), $\mathrm{D}_{2}$ occupancies peaked at $60-82 \%$ a week after injection (doses $30-50 \mathrm{mg}$ every 4 weeks). ${ }^{54}$ Four weeks later occupancies were in the range $20-74 \%$. The patients remained well despite these low occupancies.

A relatively recent study of patients responding to perphenazine decanoate found that at plasma levels of $1.8-9 \mathrm{nmol} / \mathrm{l}$ striatal $\mathrm{D}_{2}$ occupancy ranged from $66 \%$ to $82 \% .{ }^{55}$ Doses used were in the range $38-108 \mathrm{mg}$ per 2 weeks.

One study has examined $\mathrm{D}_{2}$ occupancy produced by olanzapine pamoate. ${ }^{56}$ Participants were switched from oral olanzapine to the LAI (300 mg every 4 weeks) and followed up for 6 months. Dopamine $\mathrm{D}_{2}$ receptor occupancy averaged $69 \%$ for oral olanzapine (5-20 mg per day) but then fell to around 55\% in the first month before rising to just over 60\% (all trough samples). There was no change in patients' clinical condition over the study period.

Two studies have determined $\mathrm{D}_{2}$ occupancy associated with the use of risperidone LAI. In the first, 28 patients received 2-weekly injections of $25 \mathrm{mg}, 50 \mathrm{mg}$ or $75 \mathrm{mg}$ risperidone and $\mathrm{D}_{2}$ occupancy was estimated 2 weeks after the fifth injection (i.e. at steady-state trough plasma levels): the $\mathrm{D}_{2}$ occupancies were $25-48 \%$ for $25 \mathrm{mg}, 59-83 \%$ for $50 \mathrm{mg}$ and $62-72 \%$ for $75 \mathrm{mg} .{ }^{22}$ In the second study $\mathrm{D}_{2}$ occupancies were determined for nine participants up to 3 days after injection and less than 5 days before the next injection. ${ }^{57}$ All participants had at least five injections before PET determinations were carried out. Occupancies were $53-75 \%$ for two patients receiving $25 \mathrm{mg}, 59-85 \%$ for five patients receiving $50 \mathrm{mg}$ and $71-85 \%$ for two patients receiving $75 \mathrm{mg}$.

Data on $\mathrm{D}_{2}$ occupancies associated with the use of LAIs are somewhat perplexing. They appear to show apparently subtherapeutic $\mathrm{D}_{2}$ occupancies associated with some doses, at least at some time points, without attendant relapse. This may mean that persistently high striatal $\mathrm{D}_{2}$ receptor occupancy is not required for full therapeutic effect, or that other $D_{2}$ activity outside the striatum or other receptor activities are relevant. On the other hand, the low occupancies seen with low doses of haloperidol and risperidone do fit with clinical data which suggest that these doses are suboptimal. ${ }^{31,33,48,49}$

\section{Adverse effects}

Long-acting injection formulations of FGAs might be expected to give rise to acute extrapyramidal symptoms, tardive dyskinesia 
and symptoms related to hyperprolactinaemia. ${ }^{58}$ The frequency of movement disorders and tardive dyskinesia with FGA-LAIs is similar to that seen with oral FGAs. ${ }^{59}$ Consequently the clinical utility of the LAIs is often seen to be severely limited by the likelihood of these important adverse effects (Appendix 1).

Flupentixol decanoate typically causes extrapyramidal symptoms, sedation and dry mouth. ${ }^{60}$ In one study of patients receiving $40 \mathrm{mg}$ every 3 weeks, 97\% showed signs of extrapyramidal symptoms and $82 \%$ received anti-Parkinsonian medication. ${ }^{61}$ Fluphenazine decanoate $(25 \mathrm{mg}$ every 3 weeks) in the same trial caused extrapyramidal symptoms in $97 \%$ of patients and $93 \%$ required anti-Parkinsonian medication. Rates of other important side-effects such as incident depression were virtually identical for flupentixol and fluphenazine $(53 \%$ v. $55 \%) .{ }^{61}$ Fluphenazine decanoate is also associated with blurred vision and excess salivation. ${ }^{62}$ Weight gain of more than $1 \mathrm{~kg}$ is common. ${ }^{63}$ Changes in prolactin levels seem to be dose-related. ${ }^{64}$

Haloperidol decanoate is also associated with a dose-dependent rise in plasma prolactin and in one study caused extrapyramidal symptoms severe enough to warrant anti-Parkinsonian drugs in around $90 \%$ of patients (dose averaging around $250 \mathrm{mg}$ every $2-4$ weeks). ${ }^{63}$ Although haloperidol decanoate is often assumed to give the highest risk of extrapyramidal symptoms, this has not been demonstrated in comparative studies. ${ }^{8,42,65}$ Weight gain may be less common than with fluphenazine decanoate. ${ }^{66}$

Perphenazine decanoate, like other first-generation drugs, is associated with acute extrapyramidal symptoms. Reported prevalences of such symptoms or use of anticholinergic drugs range from $29 \%{ }^{36}$ to $55 \% .{ }^{13}$ Other studies suggest high rates of extrapyramidal symptoms and hyperprolactinaemia with perphenazine enanthate, ${ }^{67,68}$ but this ester of perphenazine is known to result in much higher plasma levels of perphenazine than perphenazine decanoate. ${ }^{69}$ The total number of patients examined in well-conducted trials with either ester appears to be only $313 .^{70}$ Injection site abscesses have been reported for perphenazine enanthate. ${ }^{71}$ Weight gain seems not to occur with perphenazine decanoate. $^{36}$

Pipotiazine palmitate (mean dose $65 \mathrm{mg}$ per month) has been shown to cause similar rates of extrapyramidal symptoms as haloperidol decanoate (mean dose $100 \mathrm{mg}$ per month): $36 \%$ and $29 \%$ respectively. ${ }^{64}$ In the same study weight gain of more than $5 \mathrm{~kg}$ was more common in those receiving pipotiazine $(39 \% \mathrm{v}$. $16 \%)$. As a piperidine phenothiazine, pipotiazine might be expected to show a low incidence of extrapyramidal symptoms. There is limited evidence that pipotiazine has a relatively low potential for causing these symptoms compared with other LAIs. ${ }^{40}$

Zuclopenthixol typically causes extrapyramidal symptoms and mild autonomic effects such as postural dizziness and blurred vision. ${ }^{42}$ In one study of doses ranging from $50 \mathrm{mg}$ to $300 \mathrm{mg}$ every 2 weeks, $61 \%$ of participants experienced extrapyramidal symptoms and $78 \%$ required anti-Parkinsonian medication. ${ }^{41}$

A meta-analysis of comparative trials of FGA-LAI doses revealed no differences in the rates of extrapyramidal symptoms and tardive dyskinesia compared with oral medication and few important differences between individual LAIs. ${ }^{59}$ Other sources suggest an increased incidence of extrapyramidal symptoms and tardive dyskinesia with LAIs compared with oral antipsychotics. ${ }^{1}$ Both reviews reported an increased risk of movement disorders with fluphenazine decanoate compared with other FGA-LAIs. ${ }^{58}$ All FGA-LAIs are associated with acute and chronic local reactions at injection sites, particularly when used in high doses or injection volumes. ${ }^{72}$

Adverse effects seen with olanzapine pamoate are similar to those seen with oral olanzapine. Common side-effects include increased plasma triglycerides, weight gain, sedation and increased appetite. ${ }^{43}$ Extrapyramidal symptoms have not been reported more frequently than with oral olanzapine and the incidence of tardive dyskinesia is not known.

There has been no report of any important difference in adverse events between oral olanzapine and the LAI formulation, with the exception of a safety risk that emerged in clinical trials: post-injection syndrome. ${ }^{73}$ This came to light when an unanticipated degree of sedation was observed in a small number of patients following an injection. This adverse event has occurred in 24 patients (up to end September 2007), an incidence of $1.2 \%$ of patients treated with olanzapine pamoate or $0.07 \%$ of injections given. Post-injection syndrome consists of sedation, confusion, dizziness, altered speech/dysarthria, somnolence and/ or unconsciousness. These effects usually occur within an hour of injection, but the median time ranged from $20 \mathrm{~min}$ to $3 \mathrm{~h}$ after injection. To date all patients have fully recovered from this adverse event, usually within 3-72 h, without permanent sequelae and the majority (67\%) have continued to receive the LAI formulation. Blood samples of olanzapine plasma concentrations were taken during the events and were found to be substantially elevated (Fig. 1).

Solubility experiments have revealed that when olanzapine pamoate LAI is injected into the muscle as intended, the dissolution of the salt is gradual and results in a slow release of drug into the blood stream. However, if the salt comes into contact with a considerable amount of blood or plasma, as occurs if the needle punctures a vessel or enters a rich capillary bed during administration, the salt dissolves and therefore dissociates more quickly. Other factors thought to affect the dissolution rate of the pamoate salt are the volume and rate of blood flow and the degree of vascular injury. ${ }^{74}$

The patient should be advised about the potential risk of postinjection syndrome and needs to be observed for $3 \mathrm{~h}$ in a healthcare facility each time that the injection is administered. ${ }^{74}$ Prior to giving the injection the clinician should determine that the patient will not have to travel alone to his or her next destination. During the post-injection observation period it should be confirmed that the patient is alert and oriented and that there is no sign or symptom of overdose. If post-injection syndrome is suspected, close medical supervision and monitoring should continue until examination indicates that signs and symptoms have resolved. For the remainder of the day after injection, patients should be advised to be vigilant for signs and symptoms of overdose

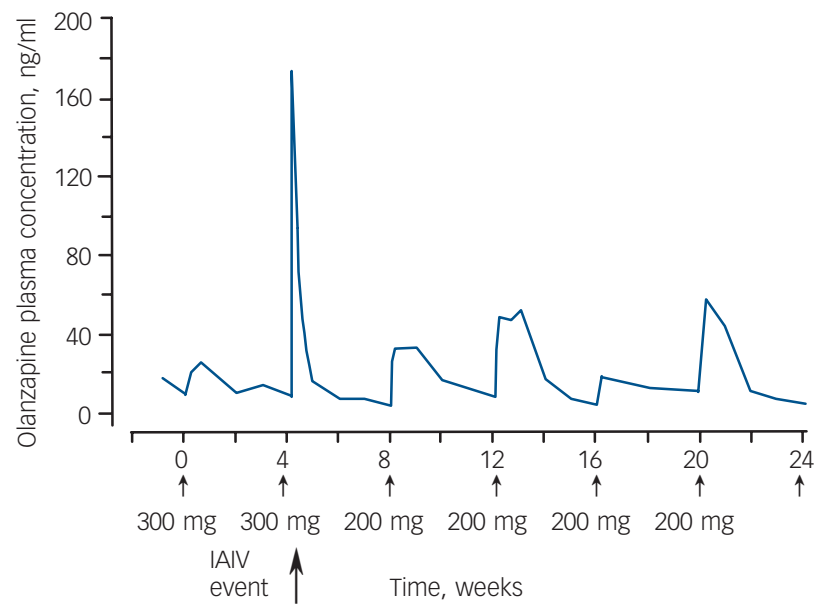

Fig. 1 Olanzapine plasma concentration profiles for a period during which six injections were administered to a patient who experienced an inadvertent intravascular (IAIV) event after the second injection. $^{75}$ 
secondary to post-injection adverse reactions, should be able to obtain assistance if needed and should not drive or operate machinery.

Risperidone LAI is associated with relatively low rates of movement disorder. ${ }^{45}$ In one study extrapyramidal symptoms were seen in $10 \%$ of participants receiving $25 \mathrm{mg}$ every 2 weeks and in $24 \%$ of those receiving $50 \mathrm{mg} .{ }^{46}$ Other studies confirm this low rate of movement disorder. ${ }^{47,76}$ Weight gain averages around $3 \mathrm{~kg}$ in the longer term (up to 1 year). ${ }^{45}$ Risperidone LAI is associated with an incidence of increased plasma prolactin similar to that seen with oral risperidone but the magnitude of this increase is lower, ${ }^{45}$ perhaps because risperidone LAI is associated with lower plasma levels of the active drug moiety. ${ }^{49}$ Injection site pain and local reactions have been carefully evaluated - pain is not usually severe and injection site reactions are rare. ${ }^{45}$ Outside clinical trials, injection site pain leading to treatment withdrawal is uncommon. ${ }^{48,77}$ Tardive dyskinesia has been shown to emerge in $1.19 \%$ of treated individuals over 1 year. $^{78}$ A similarly low incidence is also seen in more susceptible populations such as elderly patients. ${ }^{79}$ (Comparative data for FGA-LAIs are scant. One study observed an increase in the prevalence of oral tardive dyskinesia from $8 \%$ to $22 \%$ over a 3 -year period during which fluphenazine LAI or flupentixol LAI were used.) ${ }^{80}$

\section{Initiation and switching to LAIs}

The use of LAIs is confined to those who have already received antipsychotic medication: these injections should never be given to antipsychotic-naive patients. Treatment with LAIs is therefore initiated in those already taking antipsychotics or those who, for whatever reason, have recently stopped taking them. Initiation of LAIs is complicated by a number of factors (Appendix 2). First-generation antipsychotic LAIs are usually first given as a test dose, or at least at a dose at the lower end of the licensed range. These test doses are aimed at establishing patient tolerability of the drug and vehicle administered. However, test doses given in this way only really establish or otherwise the tolerability of a single, small dose of the LAI. Their use has little bearing on likely tolerability in multiple, higher-dose treatment because plasma levels at steady state are considerably higher than after a single dose. For example, in one study in which patients were given fluphenazine decanoate $50 \mathrm{mg}$ every week, plasma levels quadrupled between the end of the first week and the end of the sixth week. ${ }^{81}$ This substantial rise in plasma levels despite there being no change in dose is likely to be seen with all LAIs because of their shared long plasma half-lives, and makes sensible dose titration almost impossible. An added difficulty here is that population dose-response relationships are poorly defined for most LAIs (olanzapine, risperidone and haloperidol are the exceptions). In practice, therefore, dose optimisation is a matter largely of conjecture, and patient tolerability is often used as a proxy for dose limitation. Furthermore, the use of oral antipsychotics as 'cover' during the early stages of LAI treatment often leads to prolonged polypharmacy (there is evidence that prescribers tend not to change regimens once patients improve, presumably because to do so would be to risk relapse). ${ }^{82}$

\section{Conclusion}

All antipsychotic LAIs enable infrequent administration and assurance of adherence (or at least ready detection of non-adherence). However, appropriate prescribing of LAI preparations is clearly complicated by their shared prolonged apparent half-lives, their delayed release (particularly with risperidone) and the risk of post-injection syndrome (olanzapine). The use of test doses appears not to mitigate this complexity nor to minimise tolerability difficulties. Moreover, the lack of robust dose-response data for most preparations makes for rather approximate dosing in practice. Even with risperidone and haloperidol LAIs (for which fixed-dose studies have established the dose-response relationship) doubts persist over the clinical value of doses at the lower end of the dose range.

First-generation antipsychotic LAIs are clearly linked to high rates of extrapyramidal effects and tardive dyskinesia, among other adverse effects. There appear to be few differences between individual FGA-LAIs, although fluphenazine decanoate may be associated with a relatively higher rate of movement disorder and pipotiazine palmitate a relatively lower rate. Risperidone LAI has, on the face of it, important advantages over FGA drugs in respect of movement disorders, but its use is complicated and clinical utility compromised - by excessively delayed release and by the requirement for cold storage of the product. Olanzapine LAI also appears to have advantages over FGA formulations but its use is complicated by the risk of post-injection syndrome and by the risk of metabolic adverse effects. The apparent advantages of SGA-LAIs need to be confirmed in large-scale randomised controlled trials. It is notable that the claimed advantages of oral SGAs become less apparent when these drugs are directly compared with oral FGAs in well-conducted trials. ${ }^{83,84}$

David Taylor, BSC, MSc, PhD, MRPharmS, Pharmacy Department, Maudsley Hospital, Denmark Hill, London SE5 8AZ, UK, email: David.taylor@slam.nhs.uk and Division of Pharmaceutical Sciences, King's College London, UK

\section{Appendix 1}

\section{Adverse effects}

Extrapyramidal symptoms

symptoms are tremor, rigidity, mask-like face, reduced arm swing, drooling, dystonia (muscular spasm), oculogyric crisis, akathisia (severe inner restlessness).

Tardive dyskinesia

Tardive dyskinesia is characterised by:

a. abnormal masticatory movements (lip-smacking, licking);

b. tongue protrusion;

c. vermicular (worm-like) movement;

d. abnormal postures (tardive dystonia): opisthotonos (arching of back and neck), retrocollis (backward arching of head and neck), torticollis (sideways turn of head and neck);

e. digital abnormalities ('pill-rolling', 'piano playing', 'guitar playing');

f. grimacing.

Metabolic adverse effects

Effects include impaired glucose tolerance/diabetes mellitus, weight gain, increased triglyceride levels, increased cholesterol levels.

\section{Appendix 2}

\section{Factors complicating long-acting injection dosing}

(a) The effect of any dose is likely to be prolonged. Test doses are usually required but may not properly assess tolerability in longer-term use.

(b) Some long-acting injections (LAIS) show delayed as well as prolonged release. Cover with oral antipsychotics may be necessary. 
(c) Attainment of steady-state plasma levels is usually delayed for up to 2-3 months. During this time, plasma levels are likely to rise substantially even when dosages are not increased.

(d) Dose-response relationships are poorly defined for most LAls.

\section{References}

1 Barnes TR, Curson DA. Long-term depot antipsychotics. A risk-benefit assessment. Drug Saf 1994; 10: 464-79.

2 Jann MW, Ereshefsky L, Saklad SR. Clinical pharmacokinetics of the depot antipsychotics. Clin Pharmacokinet 1985; 10: 315-33.

3 Stauning JA, Kirk L, Joorgensen A. Comparison of serum levels after intramuscular injections of $2 \%$ and $10 \%$ cis(Z)-flupentixol decanoate in Viscoleo to schizophrenic patients. Psychopharmacology (Berl) 1979; 65: 69-72.

4 Tuninger $E$, Levander $S$. Large variations of plasma levels during maintenance treatment with depot neuroleptics. Br J Psychiatry 1996; 169: 618-21.

5 Wiles DH, Gelder MG. Plasma fluphenazine levels by radioimmunoassay in schizophrenic patients treated with depot injections of fluphenazine decanoate. Br J Clin Pharmacol 1979; 8: 565-70.

6 Curry SH, Whelpton R, De Schepper PJ, Vranckx S, Schiff AA. Kinetics of fluphenazine after fluphenazine dihydrochloride, enanthate and decanoate administration to man. Br J Clin Pharmacol 1979; 7: 325-31.

7 Ereshefsky L, Jann MW, Saklad SR, Davis CM, Richards AL, Burch NR. Effects of smoking on fluphenazine clearance in psychiatric inpatients. Biol Psychiatry 1985; 20: 329-32.

8 Kissling W, Moller HJ, Walter K, Wittmann B, Krueger R, Trenk D. Double-blind comparison of haloperidol decanoate and fluphenazine decanoate effectiveness, side-effects, dosage and serum levels during a six months treatment for relapse prevention. Pharmacopsychiatry 1985; 18: 240-5.

9 Jann MW, Saklad SR, Ereshefsky L, Richards AL, Harrington CA, Davis CM. Effects of smoking on haloperidol and reduced haloperidol plasma concentrations and haloperidol clearance. Psychopharmacology 1986; 90 : 468-70.

10 Nayak RK, Doose DR, Nair NP. The bioavailability and pharmacokinetics of oral and depot intramuscular haloperidol in schizophrenic patients. J Clin Pharmacol 1987; 27: 144-50.

11 Knudsen $P$, Hansen LB, Larsen NE. Perphenazine decanoate in sesame oil vs. perphenazine enanthate in sesame oil: a comparative study of pharmacokinetic properties and some clinical implications. Acta Psychiatr Scand Suppl 1985; 322: 11-4.

12 Larsen NE, Hansen LB. Prediction of the optimal perphenazine decanoate dose based on blood samples drawn within the first three weeks. Ther Drug Monit 1989; 11: 642-6.

13 Kistrup K, Gerlach J, Aaes-Jorgensen T, Larsen NE. Perphenazine decanoate and cis(z)-flupentixol decanoate in maintenance treatment of schizophrenic outpatients. Serum levels at the minimum effective dose.

Psychopharmacology (Berl) 1991; 105: 42-8.

14 Girard M, Granier F, Schmitt L, Cotonat J, Escande M, Blanc M. [Initial results of a pharmacokinetic study of pipothiazine and its palmitic ester (Piportil L4) in a schizophrenic population]. Encephale 1984; 10: 171-6.

15 Altamura AC, Sassella F, Santini A, Montresor C, Fumagalli S, Mundo E. Intramuscular preparations of antipsychotics: uses and relevance in clinical practice. Drugs 2003; 63: 493-512.

16 Viala A, Hou N, Ba B, Durand A, Dufour H, D'Agostino N, et al. Blood and plasma kinetics of cis(Z)-clopenthixol and fluphenazine in psychiatric patients after intramuscular injection of their decanoic esters. Psychopharmacology (Berl) 1984; 83: 147-50.

17 Poulsen JH, Olesen OV, Larsen NE. Fluctuation of serum zuclopenthixol concentrations in patients treated with zuclopenthixol decanoate in viscoleo. Ther Drug Monit 1994; 16: 155-9.

18 Jorgensen A, Overo KF. Clopenthixol and flupenthixol depot preparations in outpatient schizophrenics. III. Serum levels. Acta Psychiatr Scand Suppl 1980 279: 41-54.

19 Viala A, Ba B, Durand A, Gouezo F, Hou N, Jorgensen A. Comparative study of the pharmacokinetics of zuclopenthixol decanoate and fluphenazine decanoate. Psychopharmacology (Berl) 1988; 94: 293-7.

20 Kurtz D, Bergstrom R, McDonnell D, Mitchell M. Pharmacokinetics (PK) of multiple doses of olanzapine long-acting injection (OLAl), an intramuscular (IM) depot formulation of olanzapine (OLZ), in stabilized patients with schizophrenia. Biol Psychiatry 2008; 63 (suppl 1): 228S.

21 Ramstack M, Grandolfi GP, Mannaert E, D'Hoore P, Lasser RA. Long-acting risperidone: prolonged-release injectable delivery of risperidone using Medisorb microsphere technology. Schizophr Res 2003; 60 (suppl 1): 314.
22 Gefvert O, Eriksson B, Persson P, Helldin L, Bjorner A, Mannaert E, et al Pharmacokinetics and D2 receptor occupancy of long-acting injectable risperidone (Risperdal Consta ${ }^{\mathrm{TM}}$ ) in patients with schizophrenia. Int J Neuropsychopharmacol 2005; 8: 27-36.

23 Agrup-Andersson L, Bengtsson A, Erlandsson K, Gottfries CG, Witzell-Ostlund G. Flupenthixol decanoate. Controlled investigation concerning dosage. Acta Psychiatr Scand Suppl 1974; 255: 7-14.

24 Mccreadie RG, Flanagan WL, McKnight J, Jorgensen A. High dose flupenthixol decanoate in chronic schizophrenia. Br J Psychiatry 1979; 135: 175-9.

25 Johnson DA, Ludlow JM, Street K, Taylor RD. Double-blind comparison of half-dose and standard-dose flupenthixol decanoate in the maintenance treatment of stabilised out-patients with schizophrenia. Br J Psychiatry 1987; 151: $634-8$.

26 Cookson IB. The effects of a 50\% reduction of cis(z)-flupenthixol decanoate in chronic schizophrenic patients maintained on a high dose regime. Int Clin Psychopharmacol 1987; 2: 141-9.

27 Carpenter WT, Buchanan RW, Kirkpatrick B, Lann HD, Breier AF, Summerfelt AT. Comparative effectiveness of fluphenazine decanoate injections every 2 weeks versus every 6 weeks. Am J Psychiatry 1999; 156: 412-8.

28 Geller J. Use of extremely low doses of fluphenazine decanoate. Am J Psychiatry 1990; 147: 672.

29 Marder SR, Van Putten T, Mintz J, Lebell M, McKenzie J, May PR. Lowand conventional-dose maintenance therapy with fluphenazine decanoate. Two-year outcome. Arch Gen Psychiatry 1987; 44: 518-21.

30 Capstick N. Long-term fluphenazine decanoate maintenance dosage requirements of chronic schizophrenic patients. Acta Psychiatr Scand 1980; 61: $256-62$.

31 Kane JM, Davis JM, Schooler N, Marder S, Casey D, Brauzer B, et al. A multidose study of haloperidol decanoate in the maintenance treatment of schizophrenia. Am J Psychiatry 2002; 159: 554-60.

32 Taylor D. Establishing a dose-response relationship for haloperidol decanoate. Psychiatr Bull 2005; 29: 104-7.

33 Eklund K, Forsman A. Minimal effective dose and relapse - double-blind trial: haloperidol decanoate vs. placebo. Clin Neuropharmacol 1991; 14 (suppl 2): S7-12.

34 Omerov M, Wistedt B, Bolvig-Hansen L, Larsen NE. The relationship between perphenazine plasma levels and clinical response in acute schizophrenia. Prog Neuropsychopharmacol Biol Psychiatry 1989; 13: 159-66.

35 Mazure CM, Nelson JC, Jatlow PI, Kincare P, Bowers MB. The relationship between blood perphenazine levels, early resolution of psychotic symptoms, and side effects. J Clin Psychiatry 1990; 51: 330-4.

36 Knudsen P, Hansen LB, Hojholdt K, Larsen NE. Long-term depot neuroleptic treatment with perphenazine decanoate. I. Efficacy and side effects in a 12 month study of 42 drug monitored psychotic patients. Acta Psychiatr Scand Suppl 1985; 322: 29-40.

37 Knudsen P, Hansen LB, Hojholdt K, Larsen NE. Long-term depot neuroleptic treatment with perphenazine decanoate. II. Different depot intervals in the last 6 months of a 12 month study of 42 drug monitored psychotic patients. Acta Psychiatr Scand Suppl 1985; 322: 41-50.

38 Gallant DM, Mielke D, Bishop G, Oelsner T, Guerrero-Figueroa R. Pipotiazine palmitate: an evaluation of a new long acting intramuscular antipsychotic agent in severely ill schizophrenic patients. Dis Nerv Syst 1975; 36: 193-6.

39 Schmidt K. Pipothiazine palmitate: a versatile, sustained-action neuroleptic in psychiatric practice. Curr Med Res Opin 1986; 10: 326-9.

40 Burch EA, Ayd FJ. Depot pipotiazine 1970-1982: a review. J Clin Psychiatry 1983; 44: 242-7.

41 Solgaard T, Kistrup K, Aaes-Jorgensen T, Gerlach J. Zuclopenthixol decanoate in maintenance treatment of schizophrenic outpatients. Minimum effective dose and corresponding serum levels. Pharmacopsychiatry 1994; 27: 119-23.

42 Wistedt B, Koskinen T, Thelander S, Nerdrum T, Pedersen V, Molbjerg C. Zuclopenthixol decanoate and haloperidol decanoate in chronic schizophrenia: a double-blind multicentre study. Acta Psychiatr Scand 1991; 84: $14-21$.

43 Lauriello J, Lambert T, Andersen S, Lin D, Taylor CC, McDonnell D. An 8-week, double-blind, randomized, placebo-controlled study of olanzapine long-acting injection in acutely ill patients with schizophrenia. J Clin Psychiatry 2008; 69: 790-9.

44 Gharabawi GM, Gearhart NC, Lasser RA, Mahmoud RA, Zhu Y, Mannaert E, et al. Maintenance therapy with once-monthly administration of long-acting injectable risperidone in patients with schizophrenia or schizoaffective disorder: a pilot study of an extended dosing interval. Ann Gen Psychiatry 2007; 6: 3.

45 Moller HJ. Long-acting injectable risperidone for the treatment of schizophrenia: clinical perspectives. Drugs 2007; 67: 1541-66. 
46 Kane JM, Eerdekens M, Lindenmayer JP, Keith SJ, Lesem M, Karcher K. Long-acting injectable risperidone: efficacy and safety of the first long-acting atypical antipsychotic. Am J Psychiatry 2003; 160: 1125-32.

47 Keks NA, Ingham M, Khan A, Karcher K. Long-acting injectable risperidone $v$. olanzapine tablets for schizophrenia or schizoaffective disorder: randomised controlled, open-label study. Br J Psychiatry 2007; 191: 131-9.

48 Taylor DM, Young C, Patel MX. Prospective 6-month follow-up of patients prescribed risperidone long-acting injection: factors predicting favourable outcome. Int J Neuropsychopharmacol 2006; 9: 685-94.

49 Bai YM, Ting CT, Chen JY, Chang WH, Wu B, Hung $\mathrm{CH}$, et al. Equivalent switching dose from oral risperidone to risperidone long-acting injection: a 48-week randomized, prospective, single-blind pharmacokinetic study. J Clin Psychiatry 2007; 68: 1218-25.

50 Kapur S, Zipursky R, Jones C, Remington G, Houle S. Relationship between dopamine D2 occupancy, clinical response, and side effects: a double-blind PET study of first-episode schizophrenia. Am J Psychiatry 2000; 157: 514-20.

51 Agid O, Mamo D, Ginovart N, Vitcu I, Wilson AA, Zipursky RB, et al. Striatal vs extrastriatal dopamine D2 receptors in antipsychotic response. A double-blind PET study in schizophrenia. Neuropsychopharmacology 2006 32: 1209-15.

52 Baron JC, Martinot JL, Cambon H, Boulenger JP, Poirier MF, Caillard V, et al. Striatal dopamine receptor occupancy during and following withdrawal from neuroleptic treatment: correlative evaluation by positron emission tomography and plasma prolactin levels. Psychopharmacology (Berl) 1989; 99: 463-72.

53 Nyberg S, Farde L, Halldin C. Delayed normalization of central D2 dopamine receptor availability after discontinuation of haloperidol decanoate. Preliminary findings. Arch Gen Psychiatry 1997; 54: 953-8.

54 Nyberg S, Farde L, Halldin C, Dahl ML, Bertilsson L. D2 dopamine receptor occupancy during low-dose treatment with haloperidol decanoate. Am J Psychiatry 1995; 152: 173-8.

55 Talvik M, Nordstrom AL, Larsen NE, Jucaite A, Cervenka S, Halldin C, et al. A cross-validation study on the relationship between central D2 receptor occupancy and serum perphenazine concentration. Psychopharmacology (Berl) 2004; 175: 148-53.

56 Mamo D, Kapur S, Keshavan M, Laruelle M, Taylor CC, Kothare PA, et al. D2 receptor occupancy of olanzapine pamoate depot using positron emission tomography: an open-label study in patients with schizophrenia. Neuropsychopharmacology 2008; 33: 298-304.

57 Remington G, Mamo D, Labelle A, Reiss J, Shammi C, Mannaert E, et al. A PET study evaluating dopamine D2 receptor occupancy for long-acting injectable risperidone. Am J Psychiatry 2006; 163: 396-401.

58 Haddad PM, Taylor M, Niaz, OS. First-generation antipsychotic long-acting injections $v$. oral antipsychotric medication in schizophrenia: systematic review of randomised controlled trials and observational studies. Br J Psychiatry 2009; 195 (suppl 52): s20-8.

59 Adams CE, Fenton MKP, Quraishi S, David AS. Systematic meta-review of depot antipsychotic drugs for people with schizophrenia. Br J Psychiatry 2001; 179: 290-9.

60 Eberhard G, Hellbom E. Haloperidol decanoate and flupenthixol decanoate in schizophrenia. A long-term double-blind cross-over comparison. Acta Psychiatr Scand 1986; 74: 255-62.

61 Knights A, Okasha MS, Salih MA, Hirsch SR. Depressive and extrapyramidal symptoms and clinical effects: a trial of fluphenazine versus flupenthixol in maintenance of schizophrenic out-patients. Br J Psychiatry 1979; 135: 515-23.

62 Johnson DAW. The side-effects of fluphenazine decanoate. Br J Psychiatry 1973; 123: 519-22.

63 Chouinard G, Annable L, Campbell W. A randomized clinical trial of haloperidol decanoate and fluphenazine decanoate in the outpatient treatment of schizophrenia. J Clin Psychopharmacol 1989; 9: 247-53.

64 Bechelli LPC, lecco MC, Acioli A, Pontes MC. A double-blind trial of haloperidol decanoate and pipothiazine palmitate in the maintenance treatment of schizophrenics in a public out-patient clinic. Curr Ther Res 1985; 37: 662-71.
65 Wistedt B, Persson T, Hellbom E. A clinical double-blind comparison between haloperidol decanoate and fluphenazine decanoate. Curr Ther Res 1984; 35: 804-14.

66 Wistedt B. A comparative trial of haloperidol decanoate and fluphenazine decanoate in chronic schizophrenic patients. Int Clin Psychopharmacol 1986; 1 (suppl 1): 15-23.

67 Lindholm H, Gullberg B, Ohman A, Sedvall G. Effects of perphenazine enanthate injections on prolactin levels in plasma from schizophrenic women and men. Psychopharmacology (Berl) 1978; 57: 1-4.

68 Ahlfors UG, Dencker SJ, Gravem A, Remvig J. Clopenthixol decanoate and perphenazine enanthate in schizophrenic patients. A double-blind Nordic multicentre trial. Acta Psychiatr Scand Suppl 1980; 279: 77-91.

69 Knudsen P, Hansen LB, Auken G, Waehrens J, Hojholdt K, Larsen NE. Perphenazine decanoate vs. perphenazine enanthate: efficacy and side effects in a 6 week double-blind, comparative study of 50 drug monitored psychotic patients. Acta Psychiatr Scand Suppl 1985; 322: 15-28.

70 David A, Quraishi S, Rathbone J. Depot perphenazine decanoate and enanthate for schizophrenia. Cochrane Database Syst Rev 2005; (3): CD001717.

71 Starmark JE, Forsman A, Wahlstrom. Abscesses following prolonged intramuscular administration of perphenazine enantate. Acta Psychiatr Scand 1980; 62: 154-7.

72 Hay J. Complications at site of injection of depot neuroleptics. BMJ 1995; 311: 421.

73 McDonnell D, Sorsaburu S, Brunner E, Detke H, Anderson S, Bergstrom R, et al. Post-injection delirium/sedation syndrome observed with olanzapine long-acting injection: review of the first 25 events. Eur Neuropsychopharmacol 2008; 18 (suppl 4): S437.

74 Eli Lilly. Summary of Product Characteristics. Zypadhera $210 \mathrm{mg}, 300 \mathrm{mg}$, and $405 \mathrm{mg}$, powder and solvent for prolonged release suspension for injection. Lilly, 2009 (http://emc.medicines.org.uk/medicine/21361/SPC/ ZYPADHERA+210+mg\% $2 \mathrm{c}+300+\mathrm{mg} \% 2 \mathrm{c}+$ and $+405+\mathrm{mg} \% 2 \mathrm{c}+$ powder+and + solvent+for+prolonged+release+suspension+for+injection).

75 Eli Lilly. Psychopharmacologic Drugs Advisory Committee Briefing Document. Zyprexa Olanzapine Pamoate (OP) Depot. Olanzapine Long-Acting Injection. Schizophrenia. Lilly, 2009 (http://www.fda.gov/ohrms/dockets/ac/08/briefing/ 2008-4338b1-03-Lilly.pdf).

76 Schmauss M, Sacchetti E, Kahn JP, Medori R. Efficacy and safety of risperidone long-acting injectable in stable psychotic patients previously treated with oral risperidone. Int Clin Psychopharmacol 2007; 22: 85-92.

77 Niaz OS, Haddad PM. Thirty-five months experience of risperidone longacting injection in a UK psychiatric service including a mirror-image analysis of in-patient care. Acta Psychiatr Scand 2007; 116: 36-46.

78 Gharabawi GM, Bossie CA, Zhu Y, Mao L, Lasser RA. An assessment of emergent tardive dyskinesia and existing dyskinesia in patients receiving long-acting, injectable risperidone: results from a long-term study. Schizophr Res 2005; 77: 129-39.

79 Kissling W, Glue P, Medori R, Simpson S. Long-term safety and efficacy of long-acting risperidone in elderly psychotic patients. Hum Psychopharmacol 2007; 22: 505-13.

80 Gibson AC. Depot injections and tardive dyskinesia. Br J Psychiatry 1978; 133: $361-5$.

81 Ereshefsky L, Saklad SR, Jann MW, Davis CM, Richards A, Seidel DR. Future of depot neuroleptic therapy: pharmacokinetic and pharmacodynamic approaches. J Clin Psychiatry 1984; 45: 50-9.

82 Taylor D, Mir S, Mace S, Whiskey E. Co-prescribing of atypical and typical antipsychotics - prescribing sequence and documented outcome. Psychiatr Bull 2002; 26: 170-2.

83 Lieberman JA, McEvoy JP, Swartz MS, Rosenheck RA, Perkins DO, Keefe RS, et al. Effectiveness of antipsychotic drugs in patients with chronic schizophrenia. N Engl J Med 2005; 353: 1209-23.

84 Jones PB, Barnes TR, Davies L, Dunn G, Lloyd H, Hayhurst KP, et al. Randomized controlled trial of the effect on Quality of Life of second- vs first-generation antipsychotic drugs in schizophrenia: cost Utility of the Latest Antipsychotic Drugs in Schizophrenia Study (CUtLASS 1). Arch Gen Psychiatry 2006; 63: 1079-87. 